patients had frequent focal or generalized epileptiform discharges in waking or comatose states. Numbers or durations of discharges were counted for $10 \mathrm{~min}$ each, before, during Mozart music, after Mozart, during control Pop music, and after Pop music. Significant decreases in EEG ictal pattern duration were seen during Mozart music in 23 (79\%) patients, whereas control music had no effect. The effect was immediate or required $40-300 \mathrm{sec}$ to manifest. A carry-over inhibitory seizure effect also occurred, with fewer discharges counted after Mozart. Theta and alpha activity decreased in central areas, while delta waves increased in frontal midline areas. A direct resonance effect of Mozart music on the cerebral cortex rather than a change in alertness or emotion was suggested, since some patients were in coma or status epilepticus. (Hughes JR, Daaboul Y, Fino JJ, Shaw GL. The "Mozart Effect" on epileptiform activity. Clin Electroencephalogr July 1998;29:109-119). (Reprints: Dr John R Hughes, Univ Ill Med Ctr, M/C 796, 912 S Wood St, Chicago, IL. 60612).

COMMENT. Listening to Mozart, specifically the Sonata for Two Pianos in D Major, can lessen epileptiform activity in the EEG of patients with epilepsy, including those with status epilepticus and coma. In those with focal discharges, the effect is not limited to one temporal area, both left or right sided discharges being suppressed. The beneficial effects of Mozart and piano playing noted in children with learning problems may be extended to those with epilepsy.

\title{
DEPRESSION AND ANXIETY IN PEDIATRIC EPILEPSY
}

The frequency of depressive and anxiety-related symptoms among children and adolescents with epilepsy was determined in 44 patients, aged 7-18 years, at the State University of New York at Stony Brook, NY. Depression scores on a Child Depression Inventory and anxiety symptoms on a Child Manifest Anxiety Scale were significantly increased in $26 \%$ and $16 \%$, respectively. No patient was previously diagnosed with a mood disorder, none was mentally retarded, and few had intractable seizures. (Ettinger AB, Weisbrot DM, Nolan EE et al. Symptoms of depression and anxiety in pediatric epilepsy patients. Epilepsia June 1998;39:595599). (Reprints: Dr AB Ettinger, Epilepsy Management Program, Department of Neurology, Health Sciences Center T12-020, State University of New York at Stony Brook, Stony Brook, NY 11794).

COMMENT. Neuropsychological testing for depression and anxiety disorders can be important in the long-term management of children with epilepsy.

\section{MYOCLONIC ABSENCE SEIZURES AND CHROMOSOME ANOMALIES}

The relation between myoclonic absence-like seizures (MAS) and underlying chromosome disorders was evaluated in 14 patients at three centers in Italy. Seven (50\%) had chromosome anomalies, including trisomy $12 \mathrm{p}$ in 2 and Angelman syndrome in 4. MAS onset was at 3 years (range 4 months to 6 years), and reduced awareness and rhythmic myoclonic jerks were associated with 2- to $3-\mathrm{Hz}$ generalized spike-and-wave discharges. MAS with chromosome anomalies differed slightly from typical MAE, with earlier onset, shorter absences, and no increase in muscle tone. The GABRB3 gene may play a role in the genesis of MAS in children with mental retardation and chromosome anomalies. (Elia M, Guerrini R, Musumeci SA et al. Myoclonic absence-like seizures and chromosome abnormality syndromes. Epilepsia June 1998;39:660-663). (Reprints: Dr M Elia, Department of Neurology, OASI Institute (IRCCS), Via Conte Ruggero 73, 94018 Troina, Italy).

COMMENT. Chromosome analysis is indicated in children with myoclonic 
absence seizures and mental retardation. Resistance to therapy and learning disabilities are frequent complications of the syndrome of epilepsy with myoclonic absences (see Progress in Pediatric Neurology III, PNB Publ, 1997;p57).

Cortical myoclonus studied by magnetoencephalography is reported in 6 patients, one with Lennox-Gastaut syndrome, from Kyoto University School of Medicine, Japan (Mima T, Nagamine T, Ikeda A et al. Ann Neurol May 1998;43:598-607). Cortical myoclonus is myoclonus with preceding cortical electrical activity. Negative sharp waves at the precentral cortex are associated with myoclonus in LGS and Down syndrome, whereas surface positive activity precedes the EMG discharge in other cases. MEG permits more precise anatomical localization of cortical electomagnetic activity than does simultaneous EEG recording alone.

\section{LEARNING AND ATTENTION DISORDERS}

\section{EARLY READING SKILLS AND ADULT BRAIN ORGANIZATION}

Effects of word and pseudoword repetition on brain activation using PET and brain mapping were studied in 6 literate and 6 illiterate adults at the Hospital de Santa Maria, Lisbon, Portugal, and Karolinska Hospital, Stockholm, Sweden. Repetition of real words was $98 \%$ correct in literate and $92 \%$ correct in the illiterate group. Repetition of pseudowords was $84 \%$ correct in the literate and $33 \%$ correct in the illiterate group. Error analysis of 592 errors on pseudoword repetition showed 117 in literate and 475 in illiterate subjects. Repeating real words is a lexicosemantic and phonological process whereas pseudowords requires a pure phonological process. The required phonological processing for pseudoword repetition is dependent on the learning and knowledge of reading and writing. The absence of training in visual-phonological systems of reading and writing (orthography) in illiterate subjects explains their inability to repeat pseudowords and the lack of PET activation of areas involved in phonological processing. In pseudoword PET activation correlations, literate subjects activate several regions whereas illiterates activate only the right middle frontal region. Alterations in the functional organization of the adult brain of illiterates may be correlated with the absence of early learning experiences. (Castro-Caldas A, Petersson KM, Reis A, Stone-Elander S, Ingvar M. The illiterate brain. Learning to read and write during childhood influences the functional organization of the adult brain. Brain June 1998;121:1053-1063). (Respond: Professor A Castro-Caldas, Centro Estudos Egas Moniz, Hospital Santa Maria, 1600 Lisbon, Portugal).

COMMENT. Repetition of real words can be performed correctly by both literate and illiterate adults, and the process activates similar areas of the brain. In contrast, illiterates have difficulty repeating pseudowords, and different brain regions are activated. Learning to read and write during childhood influences the development of brain areas important in phonological processing of pseudowords.

From sensation to cognition is the title of a review article by Mesulam M-M, at Northwestern University Medical School (Brain June 1998;121:1013-1052). Attentional, motivational and emotional processes involved in the associative elaboration of sensory information and incorporation in cognition are discussed. The prefrontal cortex is critical in these attentional and motivational processes and the development of working memory. 